\title{
Histopathological Study and Categorization of Brain Tumors in Mangalore
}

\author{
Dr. Suchitra A Shetty ${ }^{1}$, Dr. Shreesha Khandige ${ }^{2}$ \\ ${ }^{1}$ Assistant Professor, Department of Pathology, Kanachur Institute of Medical Sciences, Mangalore. \\ ${ }^{2}$ Professor and HOD, Department of Pathology, Kanachur Institute of Medical Sciences, Mangalore
}

\begin{abstract}
WHO recently published its $4^{\text {th }}$ edition of classification of tumours of central nervous system (2007), incorporating a substantial number of important changes to the previous version (2000). It is important to classify because each type has a specific set of outcome and the treatment of it differs. It is important to classify because each type has a specific set of outcome and the treatment of it differs. Neuroepithelial tumours were the most common histological type followed by meningiomas and pituitary tumours. Majority of malignant intracranial tumours were WHO grade I.
\end{abstract}

Keywords: Brain, Cancer, Classification, Diagnoses, Histopathology.

\section{Introduction}

The clinicopathological aspect and role of pathologist in specific diagnosis of central nervous system (CNS) neoplasms is well understood .WHO recently published its $4^{\text {th }}$ edition of classification of tumours of central nervous system (2007), incorporating a substantial number of important changes to the previous version $(2000)$. The $4^{\text {th }}$ edition introduces 10 newly codified entities, variants and patterns; changes in grading, changes in classification of existing brain tumours as well as 1 new genetic syndrome. In the present study attempt has been made to classify the intracranial tumours according to WHO (2007) $4^{\mathrm{TH}}$ edition. ${ }^{1}$

Primary brain tumors do not spread to other body sites, and can be malignant or benign. Secondary brain tumors are always malignant. Both types are potentially disabling and life threatening ${ }^{2}$.

Although there has been a recent increase in the number of epidemiologic studies of brain cancer, little consensus exists regarding the nature and magnitude of the risk factors contributing to its development. In addition to the differences in methods and eligibility criteria used and in the representativeness of the patients studied, other confounding factors exist. There are a number of distinct types of brain cancers within the brain, and the treatments and their outcomes vary greatly based on pathologic and histologic diagnosis. More recently, researchers are identifying new therapies based on increased knowledge of cellular and molecular biology ${ }^{3}$.

It is important to classify because each type has a specific set of outcome and the treatment of it differs.

The WHO (2007) classified it as follows:

\section{Tumours of Neuroepithelial Tissue}

Astrocytic tumours

Pilocytic astrocytoma

Pilomyxoid asrocytoma

Pleomorphic xanthoastrocytoma
Diffuse astrocytoma

Fibrillary astrocytoma

Gemistocytic astrocytoma

Protoplasmic astrocytoma

Anaplastic astrocytoma

Glioblastoma

Giant cell Glioblastoma

Gliosarcoma

Gliomatosis cerebri

Oligodendroglial tumors

Oligodendroglioma

Anaplastic oligodendroglioma

Oligoastrocytic tumours

Oligoastrocytoma

Anaplastic oligoastrocytoma

Ependymal tumours

Subependymoma

Myxopapillary ependymoma

Ependymoma

Cellular

Papillary

Clear cell

Tanycytic

Anaplastic ependymoma

Choroid plexus tumours

Choroid plexus papilloma

Atypical choroid plexus papilloma

Choroid plexus carcinoma

Other neuroepithelial tumours

Astroblastoma

Chordoid glioma of the third ventricle

Angiocentric glioma

Neuronal and mixed neuronal-glial tumours Dysplastic gangliocytoma of cerebellum [Lhermitte-Duclos]

Desmoplstic infantile astrocytoma/ganglioglioma

Dysembryoplastic neuroepithelial tumour 
Gangliocytoma

Ganglioglioma

Anaplastic ganlioglioma

Central neurocytoma

Extraventriular neurcytoma

Cerebellar liponeurocytoma

Papillary glioneuronal tumour of the fourth ventricle

Paraganglioma

\section{Tumours of the pineal region}

Pineocytoma

Pineal parenchymal tumour of intermediate differentiation

Pineoblastoma

Papillary tumour of the pineal region

\section{Embryonal tumours}

Medulloblastoma

Desmoplastic nodular medulloblastoma

Medulloblastoma with extensive nodularity

Anaplastic medulloblstoma

Large cell medulloblastoma

CNS primitive neuroectodermal tumour

CNS neuroblastoma

CNS ganglioneuroblastoma

Medulloepithelioma

Ependymoblastoma

Atypical teratoid/ rhabdoid tumour

\section{Tumours of Cranial and Paraspinal Nerves}

Schwannoma [neurilemoma, neurinoma]

Cellular

Plexiform

Melanotic

Neurofibroma

Plexiform

Perineurioma

Perineurioma, NOS

Malignant perineurioma

Malignant peripheralnerve sheath tumour [MPNST]

Epithelioid MPNST

MPNST with mesenchymal differentiation

Melanotic MPNST

MPNST with glandular differentiation

\section{Tumours of the Meninges}

Tumours of meningothelial cells

Meningioma

Meningothelial

Fibrous [fibroblastic]

Transitional [mixed]

Psammomatous

Angiomatous

Microcystic

Secretory

Lymphoplasmacyte-rich

Metaplastic

Chordoid

Clear cell

Atypical

Papillary

Rhabdoid

Anaplstic [malignant]
Mesenchymal tumours

Lipoma

Angiolipoma

Hibernoma

Liposarcoma

Solitary fibrous tumour

Fibrosarcoma

Malignant fibrous histiocytoma

Leiomyosarcoma

Rhabdomyosarcoma

Chondroma

Chondrosarcoma

Osteoma

Osteosarcoma

Osteochondroma

Haemangioma

Epithelioid haemangioendothelioma

Haemangiopericytoma

Anaplastic haemangiopericytoma

Angiosarcoma

Kaposi sarcoma

Ewing sarcoma-PNET

Primay melanocytic lesions

Diffuse melanocytosis

Melanocytoma

Malignant melanoma

Meningeal melanomatosis

Other neoplasms related to the meninges

Haemangioblastoma

\section{Lymphomas and Haematopoietic Neoplasms}

Malignant lymphomas

Plasmacytoma

Granulocytic sarcoma

\section{Germ Cell Tumours}

Germinoma

Embryonal carcinoma

Yolk sac tumour

Choriocarcinoma

Teratoma

Mature

Immature

Teratoma with malignant transformation

Mixed germ cell tumour

\section{Tumours of the Sellar Region}

Craniopharyngioma

Adamantinomatous

Papillary

Granular cell tumour

Pituicytoma

Spindle cell oncocytoma of the adenohypophysis

\section{Metastatic Tumours}

Tumours of Pituitary Gland

Pituitary adenomas.

Pituitary carcinomas. 


\section{International Journal of Science and Research (IJSR)}

ISSN (Online): 2319-7064

Index Copernicus Value (2013): 6.14 | Impact Factor (2014): 5.611

\section{Aims and Objectives}

To identify and classify brain tumours using histopathology techniques.

\section{Materials and Methods}

The material used in this study was done in Tejaswini Hospital, Mangalore. The specimens were obtained from 38 cases of intracranial tumours, over a period of 2 years from May 2009 to May 2011.

Complete clinical history and clinical diagnosis were noted down in all the cases. All the specimens were from biopsy of operated tumours received in $10 \%$ formaline. They were processed by the routine paraffin embedding technique. All the tissue bits that were received were embedded, wherever necessary in multiple paraffin blocks and and sections from all these blocks were studied. Paraffin sections of 4 microns thickness were obtained from each block and stained with haematoxyline and eosine stain using standard procedures. Histochemical stains were performed wherever indicated.

\section{Results}

\section{India and Abroad}

\begin{tabular}{|c|c|} 
Histological Type & Present Study \\
Neuroepithelial tumour & 31.6 \\
\hline Cranial nerve tumours & 10.5 \\
\hline Meningeal tumours & 30.0 \\
\hline Tumours of sellar region & 2.6 \\
\hline Lymphomas & 2.6 \\
\hline Metastatic tumour & 7.9 \\
Pituitary tumour & 15.8 \\
Total & 38 \\
\hline
\end{tabular}

\section{Discussion}

When the present study is compared with the other study the following are noted

\begin{tabular}{|c|c|c|c|c|c|c|c|}
\hline Histological type & $\begin{array}{c}\text { Present } \\
\text { study }\end{array}$ & $\begin{array}{l}\text { Banerjee et al, } \\
\text { Chandigarh }^{52}\end{array}$ & $\begin{array}{l}\text { Pal AK and } \\
\text { Chopra et al } \\
\text {,Lucknow }\end{array}$ & $\begin{array}{c}\text { Dastur And } \\
\text { Lalitha et al. } \\
\text { Bombay }^{123}\end{array}$ & $\begin{array}{l}\text { Verma et al } \\
\text {, Pune }^{32}\end{array}$ & $\begin{array}{l}\text { Katsura e } t \\
\text { al, Japan }^{33}\end{array}$ & $\begin{array}{c}\text { Fan et al } \\
\text { USA }\end{array}$ \\
\hline $\begin{array}{l}\text { Neuroepithelial } \\
\text { tumour }\end{array}$ & 31.6 & 55.40 & 64.7 & 50.25 & 61.68 & 31.68 & 65.79 \\
\hline $\begin{array}{l}\text { Cranial nerve } \\
\text { tumours }\end{array}$ & 10.5 & 6.80 & 5.0 & 9.77 & 4.95 & 11.85 & 2.83 \\
\hline Meningeal tumours & 30.0 & 20.30 & 15.1 & 13.67 & 14.83 & 15.71 & 13.84 \\
\hline $\begin{array}{l}\text { Tumours of sellar } \\
\text { region }\end{array}$ & 2.6 & 1.7 & 4.2 & 0.60 & 3.18 & 9.44 & -- \\
\hline Lymphomas & 2.6 & -- & -- & 0.60 & 0.71 & - & -- \\
\hline Metastatic tumour & 7.9 & 1.7 & -- & 7.60 & 3.89 & 4.28 & -- \\
\hline Pituitary tumour & 15.8 & 3.4 & 7.6 & 6.95 & 7.6 & 10.84 & 9.69 \\
\hline Total & 38 & 177 & 100 & 1844 & 283 & 3367 & 16311 \\
\hline
\end{tabular}

\section{Conclusion}

- Neuroepithelial tumours were the most common histological type followed by meningiomas and pituitary tumours.

- Majority of malignant intracranial tumours were WHO grade I.

- Rare variant like clear cell type was also observed.

- .Craniopharyngiomas do not necessarily occur in 4-6 years as projected in other studies because occurrence at 54 years has been recorded in the present study.

- Most meningiomas were of grade I, but most astrocytomas were of higher grade.

- Germ cell tumours were rare, in the present study their incidence was nil.

- One case of neuroblastoma was interesting for family study but was not possible due to insufficient follow up.

\section{References}

[1] Brat DJ, Parisi JE, DeMasters BKK et al. Surgical Neuropathology update. A review of changes introduced by the WHO classification of tumours of the central nervous system, $4^{\text {th }}$ Edition. Arch Pathol Lab Med 2008 ; 132 : 993-1007.
[2] American Cancer Society. 1999a. Brain and Spinal Cord Cancers of Adults. Available at: http://www3.cancer. org/cancerinfo/.

[3] Carrie A M, Timothy F C. Brain tumor treatment: chemotherapy and other new developments. Seminars in Oncology Nursing 2004; 20(4): 260-272. 